This item was submitted to Loughborough's Research Repository by the author.

Items in Figshare are protected by copyright, with all rights reserved, unless otherwise indicated.

Inflation, variability, and the evolution of human capital in a model with transactions costs

PLEASE CITE THE PUBLISHED VERSION

LICENCE

CC BY-NC-ND 4.0

REPOSITORY RECORD

Varvarigos, Dimitrios. 2019. "Inflation, Variability, and the Evolution of Human Capital in a Model with Transactions Costs". figshare. https://hdl.handle.net/2134/2402. 
This item was submitted to Loughborough's Institutional Repository by the author and is made available under the following Creative Commons Licence conditions.

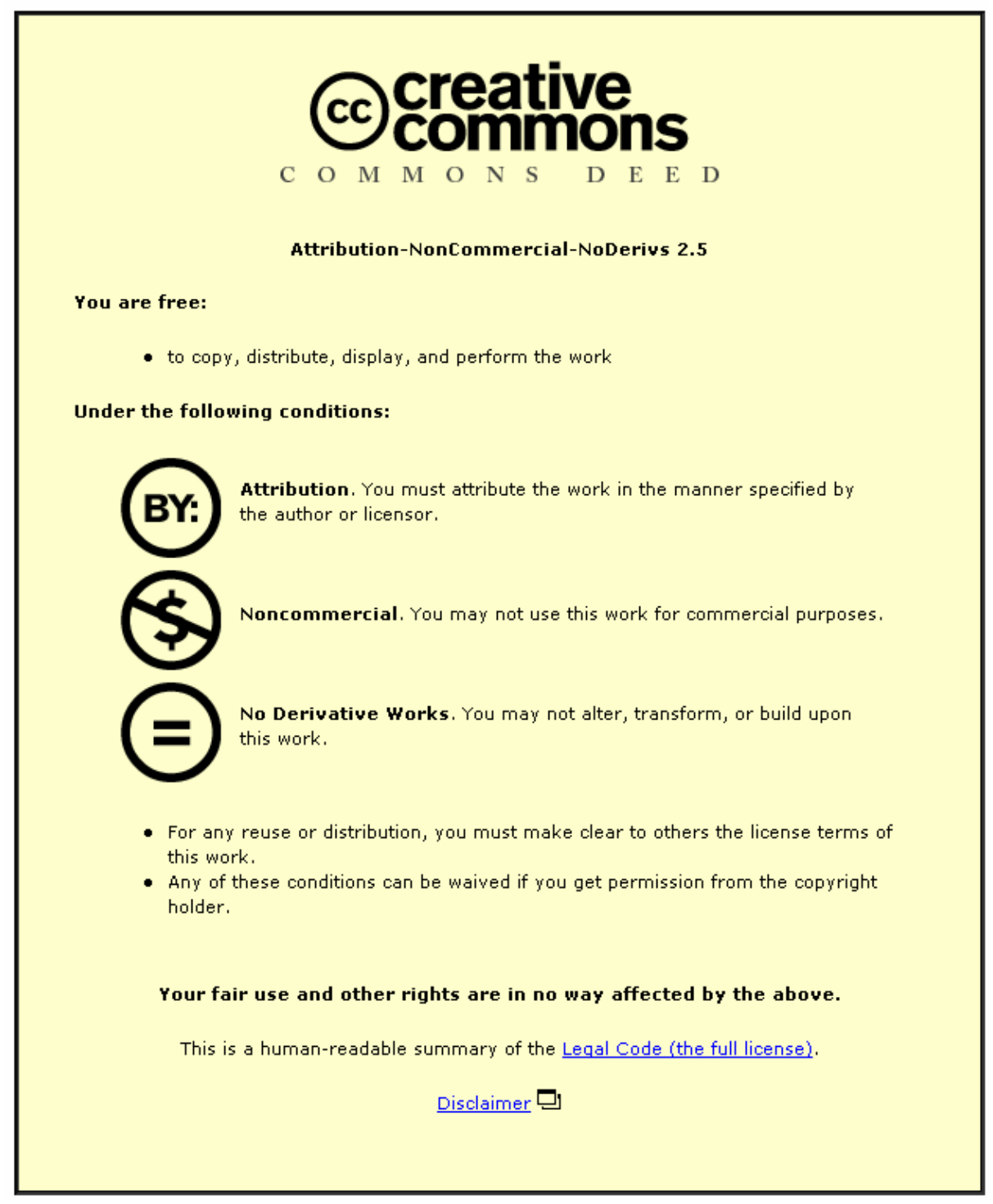

For the full text of this licence, please go to: http://creativecommons.org/licenses/by-nc-nd/2.5/ 


\title{
Inflation, Variability, and the Evolution of Human Capital in a Model with Transactions Costs
}

\author{
Dimitrios Varvarigos \\ Department of Economics, Loughborough University \\ Loughborough, Leicestershire LE11 3TU, U.K.
}

\begin{abstract}
:
In a monetary growth model, I show that average inflation inhibits growth while inflation volatility enhances it. The effect of nominal volatility on human capital accumulation depends on the response of money demand and the corresponding extent of transactions costs rather than from a direct, precautionary motive.
\end{abstract}

Keywords: Money; Growth; Volatility

JEL classification: E32; E60; O42

\section{Introduction}

Following the emergence of what is generally branded as "endogenous growth theory", researchers have renewed their interest on the circumstances under which nominal phenomena, like inflation, impinge on trend growth, through their effect on optimal decisions concerning investment, education etc. (e.g., Jha et al, 2002; Gillman and Kejak, 2005; Ho, 1996; van der Ploeg and Alogoskoufis, 1994). However, few analyses have considered the effects of nominal (or inflation) variability on long-run growth. Dotsey and Sarte (2000) employ an 'AK'-type model with a CIA constraint and argue that inflation variability enhances growth by stimulating physical capital investment via a precautionary motive in response to nominal uncertainty. Blackburn and Pelloni (2004) use a model with nominal rigidities and argue that nominal variability exerts a negative effect on growth, channeled through its adverse impact on aggregate employment. 
In this paper I construct a model where growth is driven by purposeful accumulation of human capital, and non-neutrality arises because money balances reduce the real resource costs associated with transactions. Like Dotsey and Sarte (2000) I find that trend growth is inversely related with permanent money growth but positively related with its volatility. However, the mechanism leading to the later result is quite different as it does not lie to a direct precautionary increase in investment. Instead, it lies on how money holdings react to changes in inflation and its variability, the corresponding change in the transactions costs and, subsequently, the optimal response of learning effort to changes in the net return to output production.

\section{The Model}

There is a mass (normalised to unity) of infinitely-lived, identical producers-consumers of the economy's single commodity. A representative agent produces $y_{t}$ units of output by combining her existing stock of human capital, $h_{t}$, with effort, $n_{t}$, according to

$$
y_{t}=n_{t} h_{t} \text {. }
$$

Assuming full depreciation, human capital evolves according to $h_{t+1}=i_{t}$, where $i_{t}$ denotes investment in human capital. The individual undertake this investment by combining effort, $u_{t}$, together with the existing stock of knowledge, $h_{t}$, according to $i_{t}=\mathrm{H} u_{t}^{\eta} h_{t}$, where $\mathrm{H}>0$ and $\eta \in(0,1)$. Therefore, the law of motion for human capital is given by

$$
h_{t+1}=\mathrm{H} h_{t} u_{t}^{\eta} .
$$

Following Jha et al (2002), I assume that there are transactions costs associated with the consumption of goods. Specifically, the consumption of $c_{t}$ units requires the agent to forego a fraction $q_{t} \in(0,1)$ of her available income. The role of money is to facilitate these transactions, by reducing the resource costs associated with them. We can approach this idea by assuming that $q_{t}=Q\left(c_{t}, \frac{m_{t-1}+\omega_{t}}{p_{t}}\right)$ with $Q_{1}>0, Q_{2}<0$ and where $m_{t-1}$ denotes the end of period- $t-1$ nominal value of money holdings, $\omega_{t}$ is a monetary injection by the 
government and $p_{t}$ is the price level. ${ }^{1}$ A specific functional form for the transactions cost function is

$$
Q(\cdot)=1-\Psi\left(\frac{m_{t-1}+\omega_{t}}{p_{t} c_{t}}\right)^{\psi}, \Psi, \psi \in(0,1),
$$

such as $\lim _{j \rightarrow 0} Q(j)=1$ and $\lim _{j \rightarrow 1} Q(j)=\Psi<1$.

The representative agent receives utility from consumption and disutility from total effort according to

$$
V=E_{0} \sum_{t=0}^{\infty} \beta^{t} \log \left[c_{t}-h_{t}\left(n_{t}+u_{t}\right)^{\varepsilon}\right], \varepsilon>1, \beta \in(0,1),
$$

where $E_{0}$ is the conditional expectations operator. ${ }^{2}$ The per-period budget constraint is

$$
c_{t}+\frac{m_{t}}{p_{t}}=\left(1-q_{t}\right) y_{t}+\frac{m_{t-1}}{p_{t}}+\frac{\omega_{t}}{p_{t}} .
$$

The set-up is completed by assuming that money supply evolves according to $m_{t}^{s}=m_{t-1}^{s}+\omega_{t}$. I also assume that the monetary injection, $\omega_{t}$, is stochastically proportional to $m_{t-1}^{s}$ according to $\omega_{t}=\mu_{t} m_{t-1}^{s}$, where $\mu_{t}$ is a sequence of bounded, positively valued, i.i.d. random variables with mean $\tilde{\mu}$ and variance $\sigma_{\mu}^{2}$. Therefore,

$$
m_{t}^{s}=\left(1+\mu_{t}\right) m_{t-1}^{s} \text {. }
$$

\section{General Equilibrium and Growth}

Definition. Given the initial values $h_{0}, m_{0}>0$, a dynamic, competitive equilibrium is a sequence of quantities $\left\{c_{t}, y_{t}, n_{t}, u_{t}, q_{t}, m_{t}, m_{t}^{s}, \omega_{t}, \mu_{t}, p_{t}, h_{t+1}\right\}_{t=0}^{\infty}$ such that:

(i) Given $\left\{m_{t}^{s}, \omega_{t}, \mu_{t}, p_{t}\right\}_{t=0}^{\infty}$, the quantities $\left\{c_{t}, y_{t}, n_{t}, u_{t}, m_{t}, h_{t+1}\right\}_{t=0}^{\infty}$ solve the representative agent's optimisation problem.

(ii) $n_{t}$ and $u_{t}$ are stationary.

\footnotetext{
1 Although my results would be identical, qualitatively, I choose to use the beginning of period- $t$ rather than the end of period- $t$ money holdings in the cost function. This seems more appropriate given the role of money to facilitate transactions.

2 This type of utility incorporates the foregone leisure as an input to home production activities. For a detailed discussion, see Hercowitz and Sampson (1991).
} 
(iii) The goods market clears every period, i.e., $c_{t}=\left(1-q_{t}\right) y_{t} \forall t \geq 0$.

(iv) The money market clears every period, i.e., $m_{t}=m_{t}^{s} \forall t \geq 0$.

The individual's objective is to maximise (4) subject to (1), (2), (3) and (5). Denote the Lagrange multipliers associated with (5) and (2) by $\lambda_{t}$ and $\xi_{t}$ respectively. The equilibrium of the model can be derived from the first order conditions, associated with the maximisation problem, together with the transversality conditions on real money balances, $\lim _{\tau \rightarrow \infty} \beta^{\tau}\left(\lambda_{t+\tau} \frac{m_{t+\tau}}{p_{t+\tau}}\right)=0$, and human capital, $\lim _{\tau \rightarrow \infty} \beta^{\tau}\left(\xi_{t+\tau} h_{t+\tau+1}\right)=0$.

After appropriate manipulation of the first order conditions, one can get the following:

$$
\begin{gathered}
\varepsilon\left(n_{t}+u_{t}\right)^{\varepsilon-1}=\frac{\Psi}{1+\psi}\left(\frac{m_{t}}{p_{t} c_{t}}\right)^{\psi}, \\
\frac{\varepsilon h_{t}\left(n_{t}+u_{t}\right)^{\varepsilon-1}}{c_{t}-h_{t}\left(n_{t}+u_{t}\right)^{\varepsilon}}=\frac{\eta \xi_{t} h_{t+1}}{u_{t}}, \\
\lambda_{t} \frac{m_{t}}{p_{t}}=\beta E_{t}\left[\lambda_{t+1} \frac{m_{t+1}}{p_{t+1}}\left(\frac{1}{1+\mu_{t+1}}\right)\right] \\
+\beta E_{t}\left[\lambda_{t+1} \psi \Psi\left(\frac{m_{t+1}}{p_{t+1} c_{t+1}}\right)^{\psi} n_{t+1} h_{t+1}\left(\frac{1}{1+\mu_{t+1}}\right)\right], \\
\xi_{t} h_{t+1}=\beta E_{t}\left(\xi_{t+1} h_{t+2}\right)+\beta E_{t}\left[\lambda_{t+1} \Psi\left(\frac{m_{t+1}}{p_{t+1} c_{t+1}}\right)^{\psi} n_{t+1} h_{t+1}\right] \\
-\beta E_{t}\left[\frac{h_{t+1}\left(n_{t+1}+u_{t+1}\right)^{\varepsilon}}{c_{t+1}-h_{t+1}\left(n_{t+1}+u_{t+1}\right)^{\varepsilon}}\right] .
\end{gathered}
$$

Before I proceed to the equilibrium results of this model, I introduce some well-known concepts that will facilitate the subsequent analysis.

Theorem. Let $x$ be a random variable and $f(x)$ a continuous function. A mean preserving spread in the distribution of $x$ increases (decreases) $E[f(x)]$ if the function $f(x)$ is convex (concave). 
Corollary. Let the mean and the variance of $x$ be given by $\tilde{x}$ and $\sigma_{x}^{2}$ respectively. Then, $E[f(x)]=g\left(\tilde{x}, \sigma_{x}^{2}\right)$ where $\operatorname{sign}\left[g_{1}(\cdot)\right]=\operatorname{sign}\left[f_{x}(\cdot)\right]$ and $\operatorname{sign}\left[g_{2}(\cdot)\right]=\operatorname{sign}\left[f_{x x}(\cdot)\right]$.

Given the transversality condition on real money balances, I proceed by guessing that, in equilibrium, $\lambda_{t}=\frac{\Theta}{c_{t}}$ and $\frac{m_{t}}{p_{t} c_{t}}=\Omega$, where $\Theta$ and $\Omega$ will be composite terms of the model's structural parameters of preferences and technologies. Consequently, we can get the following result:

Proposition 1. The ratio of real money balances-to-consumption falls as a result of a permanent increase in money growth and increases as a result of an increase in the variability of money growth.

Proof. After the appropriate substitutions, (9) can be written as

$$
\Omega=\beta \Omega E_{t}\left[1 /\left(1+\mu_{t+1}\right)\right]+\beta \psi E_{t}\left[1 /\left(1+\mu_{t+1}\right)\right]
$$

According to the Corollary, we have $E_{t}\left[1 /\left(1+\mu_{t+1}\right)\right]=\delta\left(\tilde{\mu}, \sigma_{\mu}^{2}\right)<1$ with $\delta_{1}(\cdot)<0$ and $\delta_{2}(\cdot)>0$. Then, from (11) it follows that $\Omega \equiv \frac{m_{t}}{p_{t} c_{t}}=\frac{\beta \psi \delta\left(\tilde{\mu}, \sigma_{\mu}^{2}\right)}{1-\beta \delta\left(\tilde{\mu}, \sigma_{\mu}^{2}\right)}$. Clearly, $\operatorname{sign}[\partial \Omega / \partial \tilde{\mu}]=\operatorname{sign}\left[\delta_{1}(\cdot)\right]$ and $\operatorname{sign}\left[\partial \Omega / \partial \sigma_{\mu}^{2}\right]=\operatorname{sign}\left[\delta_{2}(\cdot)\right] \cdot^{3}$

The intuition behind the effect of the permanent part of money growth $(\tilde{\mu})$ on money demand is as follows: Equations (9) and (11) display the optimality condition equating the (current) utility cost with the (discounted future) expected utility benefit resulting from a marginal increment in real money holdings. Following a permanent increase in money growth, individuals expect the future real value of money holdings to be lower due to higher expected inflation. As the future benefit of holding money falls together with its real value, the demand for money drops as well.

The effect of nominal volatility $\left(\sigma_{\mu}^{2}\right)$ on money demand depends crucially on the fact that the discounted future benefit from holding money depend on the expected value of a convex

\footnotetext{
3 This solution satisfies the transversality condition on real money and can be verified by direct substitution back in (9). To ensure $m_{t} / p_{t} c_{t} \leq 1, \mathrm{I}$ impose the parameter restriction $\delta\left(\tilde{\mu}, \sigma_{\mu}^{2}\right) \leq 1 /[(1+\psi) \beta]$.
} 
function of the random variable $\mu_{t+1}$. This indicates that the individual perceives the expected decrease in the benefit from holding money, resulting from an increase in $\mu_{t+1}$, to be less pronounced than the expected increase in the benefit from holding money, resulting from an equal decrease in $\mu_{t+1}$. On average, individuals react to variations in the real utility return on money by increasing the holdings of this asset.

To obtain the equilibrium solutions for labour, $n_{t}$, and learning, $u_{t}$, we can combine equations (7), (8) and (11), manipulate algebraically and use the transversality condition on human capital. Eventually, we can get

$$
\begin{aligned}
& n_{t}=\tilde{n}=\frac{1}{1+Z}\left[\frac{\Psi}{(1+\psi) \varepsilon}\right]^{1 /(\varepsilon-1)}\left(\frac{\beta \psi \delta\left(\tilde{\mu}, \sigma_{\mu}^{2}\right)}{1-\beta \delta\left(\tilde{\mu}, \sigma_{\mu}^{2}\right)}\right)^{\psi /(\varepsilon-1)}=N\left(\tilde{\mu}, \sigma_{\mu}^{2}\right), \\
& u_{t}=\tilde{u}=\frac{Z}{1+Z}\left[\frac{\Psi}{(1+\psi) \varepsilon}\right]^{1 /(\varepsilon-1)}\left(\frac{\beta \psi \delta\left(\tilde{\mu}, \sigma_{\mu}^{2}\right)}{1-\beta \delta\left(\tilde{\mu}, \sigma_{\mu}^{2}\right)}\right)^{\psi /(\varepsilon-1)}=U\left(\tilde{\mu}, \sigma_{\mu}^{2}\right) .
\end{aligned}
$$

where $Z=\frac{\eta \beta[\varepsilon(1+\psi)-1](1-\Theta \psi)}{\varepsilon(1-\beta)+\eta \beta(1-\Theta \psi)}$ and $\Theta=\frac{\varepsilon(1-\beta)+\eta \beta}{[\varepsilon(1+\psi)-1](1-\beta)+\eta \beta \psi}$.

Proposition 2. A permanent increase in money growth results in a decrease of the equilibrium effort levels for both labour and learning. An increase in the variability of money growth results in an increase of the equilibrium effort levels for both labour and learning.

Proof. Recall that $\partial \delta(\cdot) / \partial \tilde{\mu}<0$ and $\partial \delta(\cdot) / \partial \sigma_{\mu}^{2}>0$. From (12) and (13), we can determine that $\operatorname{sign}\left[N_{j}(\cdot)\right]=\operatorname{sign}\left[U_{j}(\cdot)\right]=\operatorname{sign}\left[\delta_{j}(\cdot)\right]$ for $j=1,2$.

The underlying rationale behind Proposition 2 is the following: A decrease in the permanent part of money growth and/or an increase in its volatility enhances the marginal benefit from producing output as they mitigate the resource costs of transactions indirectly through the increase in real money holdings. To restore equilibrium, individuals will act as to increase the marginal cost of producing more output - that is, they will act as to increase the marginal disutility from labour. This equilibrium adjustment is transparent in equation (7). Observing the left hand side of (7), it is clear that individuals can increase the marginal 
disutility from labour by adjusting not only labour effort itself but also the effort associated with learning. As it turns out, in equilibrium both types of effort adjust at the same direction in response to changes in the first and second moments of the random money growth's distribution.

I will complete the analysis by illustrating the effects of inflation and its variability on trend growth.

Lemma. In equilibrium, the economy moves along a balanced growth path in which output and consumption grow at the same rate as human capital.

Proof. This is clear from (1), (3), (12), (13), the goods market clearing condition and Proposition 1.

Proposition 3. A permanent increase in money growth inbibits the growth rate while an increase in the variability of money growth stimulates it.

Proof. According to the Lemma, $\quad \gamma=\frac{y_{t+1}}{y_{t}}=\frac{c_{t+1}}{c_{t}}=\frac{h_{t+1}}{b_{t}}=\mathrm{H} \tilde{u}^{\eta} . \quad$ Clearly, $\operatorname{sign}[\partial \gamma / \partial \tilde{\mu}]=\operatorname{sign}\left[U_{1}(\cdot)\right]$ and $\operatorname{sign}\left[\partial \gamma / \partial \sigma_{\mu}^{2}\right]=\operatorname{sign}\left[U_{2}(\cdot)\right]$. The proof then follows from the results of Proposition 2.

Intuitively, as the growth rate is a monotonically increasing function of learning effort, the effects of permanent money growth and its volatility on $\tilde{u}$ will be transmitted to the growth rate of human capital, output and consumption.

\section{Summary}

The present analysis can be thought as complementary to the seminal contribution of Dotsey and Sarte (2000), as it identifies a new channel for the possible effects of nominal variability on growth. Rather than resting to a direct precautionary increase in productive (in this case, human) capital, a positive growth effect of money growth volatility arises because it induces an increase in holdings of real money balances, hence reducing the transactions costs 
associated with consumption. As individuals face the potential of permanently more disposable income resources from producing output, they are induced to increase the inputs of production - i.e., labour effort and, more importantly for growth, human capital. The effect of average money growth works in a similar manner.

\section{References}

1. Blackburn, K., and A. Pelloni. 2004. 'On the relationship between growth and volatility', Economics Letters, 83, 123-127

2. Dotsey, M., and P.D. Sarte. 2000. 'Inflation uncertainty and growth in a cash-inadvance economy', Journal of Monetary Economics, 45, 631-655

3. Gillman, M., and M. Kejak. 2005. 'Inflation and balanced-path growth with alternative payment mechanisms', Economic Journal, 115, 247-270

4. Hercowitz, Z., and M. Sampson. 1991. 'Output growth, the real wage, and employment fluctuations', American Economic Review, 81, 1215-1237

5. Ho, W. 1996. 'Imperfect information, money, and economic growth', Journal of Money, Credit and Banking, 28, 578-603

6. Jha, S.K., Wang, P., and C.K. Yip. 2002. 'Dynamics in a transactions-based monetary growth model', Journal of Economic Dynamics and Control, 26, 611-635

7. van der Ploeg, F., and G. Alogoskoufis. 1994. 'Money and endogenous growth', Journal of Money, Credit and Banking, 24, 771-791

\section{Appendix:}

The first order conditions associated with the maximisation problem are the following:

$$
\begin{gathered}
\frac{1}{c_{t}-h_{t}\left(n_{t}+u_{t}\right)^{\varepsilon}}=\lambda_{t}\left[1+\psi \Psi\left(\frac{m_{t-1}+\omega_{t}}{p_{t} c_{t}}\right)^{\psi} \frac{n_{t} h_{t}}{c_{t}}\right], \\
\frac{\varepsilon h_{t}\left(n_{t}+u_{t}\right)^{\varepsilon-1}}{c_{t}-h_{t}\left(n_{t}+u_{t}\right)^{\varepsilon}}=\lambda_{t} \Psi\left(\frac{m_{t-1}+\omega_{t}}{p_{t} c_{t}}\right)^{\psi} h_{t}, \\
\frac{\varepsilon h_{t}\left(n_{t}+u_{t}\right)^{\varepsilon-1}}{c_{t}-h_{t}\left(n_{t}+u_{t}\right)^{\varepsilon}}=\eta \xi_{t} \mathrm{H} h_{t} u_{t}^{\eta-1},
\end{gathered}
$$




$$
\begin{aligned}
& \frac{\lambda_{t}}{p_{t}}=\beta E_{t}\left(\frac{\lambda_{t+1}}{p_{t+1}}\right)+\beta E_{t}\left[\lambda_{t+1} \psi \Psi\left(\frac{m_{t}+\omega_{t+1}}{p_{t+1} c_{t+1}}\right)^{\psi-1} \frac{n_{t+1} h_{t+1}}{p_{t+1} c_{t+1}}\right], \\
& \xi_{t}=\beta E_{t}\left(\xi_{t+1} \mathrm{H} u_{t+1}^{\eta}\right)+\beta E_{t}\left[\lambda_{t+1} \Psi\left(\frac{m_{t}+\omega_{t+1}}{p_{t+1} c_{t+1}}\right)^{\psi} n_{t+1}\right] \\
&-\beta E_{t}\left[\frac{\left(n_{t+1}+u_{t+1}\right)^{\varepsilon}}{c_{t+1}-b_{t+1}\left(n_{t+1}+u_{t+1}\right)^{\varepsilon}}\right] .
\end{aligned}
$$

Given the money market clearing condition and equation (6), we have

$$
m_{t}=m_{t-1}+\omega_{t}=\left(1+\mu_{t}\right) m_{t-1} .
$$

Combining (1), (3), (A6) and the goods market clearing condition yields

$$
c_{t}=\Psi\left(\frac{m_{t}}{p_{t} c_{t}}\right)^{\psi} n_{t} h_{t} .
$$

\section{Derivation of (9) and (10) and (11):}

Equation (9) is derived after multiplying both sides of (A4) by $m_{t}$ and using equation (A6).

After multiplying both sides of (A5) by $h_{t+1}$ and using (2) we get equation (10). Equation

(11) can be derived after substitution of $\lambda_{t}=\frac{\Theta}{c_{t}}, \frac{m_{t}}{p_{t} c_{t}}=\Omega$ and (A7) in (9).

\section{Derivation of (7) and (8):}

After substitution of (A6) and (A7) in (A1) we get

$$
\frac{1}{(1+\psi)\left[c_{t}-h_{t}\left(n_{t}+u_{t}\right)^{\varepsilon}\right]}=\lambda_{t}
$$

Substitution of (A6) and (A8) in (A2) yields equation (7) To get equation (8), use (2) in (A3).

\section{Derivation of (12) and (13):}

Substitute (A7) and (A8) in (10)

$$
\begin{aligned}
\xi_{t} h_{t+1} & =\beta E_{t}\left(\xi_{t+1} h_{t+2}\right)+\beta E_{t}\left\{\frac{c_{t+1}}{(1+\psi)\left[c_{t+1}-h_{t+1}\left(n_{t+1}+u_{t+1}\right)^{\varepsilon}\right]}\right\} \\
& -\beta E_{t}\left[\frac{h_{t+1}\left(n_{t+1}+u_{t+1}\right)^{\varepsilon}}{c_{t+1}-h_{t+1}\left(n_{t+1}+u_{t+1}\right)^{\varepsilon}}\right] .
\end{aligned}
$$


Now add and subtract the term $\beta E_{t}\left\{\frac{c_{t+1}}{\left[c_{t+1}-b_{t+1}\left(n_{t+1}+u_{t+1}\right)^{\varepsilon}\right]}\right\}$ in the RHS of equation (A9). Then combining (A8) with the original guess that $\lambda_{t}=\frac{\Theta}{c_{t}}$, substituting in (A9) and rearranging yields

$$
\xi_{t} h_{t+1}=\beta E_{t}\left(\xi_{t+1} h_{t+1}\right)+\beta(1-\Theta \psi) .
$$

This is a stochastic, difference equation with solution

$$
\xi_{t} h_{t+1}=\frac{\beta(1-\Theta \psi)}{1-\beta} .
$$

The solution in (A11) satisfies the transversality condition for human capital and can be verified by direct substitution back in (A10).

Equation (7) in the main text can be rewritten as

$$
\left(n_{t}+u_{t}\right)^{\varepsilon}=\frac{\Psi}{\varepsilon(1+\psi)}\left(\frac{m_{t}}{p_{t} c_{t}}\right)^{\psi}\left(n_{t}+u_{t}\right) .
$$

Substitute (A7), A(11) and (A12) in (8) and then cancel terms as to get

$$
\frac{\frac{1}{1+\psi}}{n_{t}-\frac{n_{t}+u_{t}}{\varepsilon(1+\psi)}}=\frac{\eta \beta(1-\Theta \psi)}{(1-\beta) u_{t}} .
$$

Solving this equation for $u_{t}$ yields

$$
u_{t}=\mathrm{Z} n_{t}
$$

where the solution for $\mathrm{Z}$ is given in the main text. Now, substitute (A14) in (7) and solve for $n_{t}$ as to get equation (12). The solution for $u_{t}$ in equation (13) can be derived simply by substituting (12) in (A14).

\section{Derivation of the composite parameter term $\Theta$ :}

We need to find the solution for $\Theta$ as to ensure the existence of equilibrium. Given (A8), we have

$$
\frac{1}{(1+\psi)\left[c_{t}-b_{t}\left(n_{t}+u_{t}\right)^{\varepsilon}\right]}=\frac{\Theta}{c_{t}}
$$


Substitute (A7), (A12) and A(14) in (A15), cancel terms and then rearrange as to get

$$
\Theta=\frac{\varepsilon}{\varepsilon(1+\psi)-1-Z}
$$

Now use $Z$ as to get the solution for $\Theta$ from (A16). As given in the main text, this turns out to be $\Theta=\frac{\varepsilon(1-\beta)+\eta \beta}{[\varepsilon(1+\psi)-1](1-\beta)+\eta \beta \psi}$. This solution is positive, unique, and it also satisfies $\Theta \psi<1$ as long as $\varepsilon>1$ (which holds by assumption), ensuring that the equilibrium solution for learning is positive. 